\title{
Kemik iliği ödemi ve osteonekroz
}

\section{Bone marrow edema and osteonecrosis}

\author{
Toygun Kağan Eren ${ }^{1}$, Cem Nuri Aktekin ${ }^{1,2}$ \\ ${ }^{1}$ Ankara Eğitim ve Araştırma Hastanesi, Ortopedi ve Travmatoloji Kliniği, Ankara \\ ${ }^{2}$ Ankara Yıldırım Beyazıt Üniversitesi Tıp Fakültesi, Ortopedi ve Travmatoloji Anabilim Dalı, Ankara
}

\begin{abstract}
Kemik iliği ödemi, vücutta birçok farklı lokasyonda ortaya çıkabilen, farklı hastalıklarla ilişkili olabilen ve klinikte sıklıkla karşılaşılan bir bulgudur. Bu değişken nedenler arasında osteonekroz da önemli bir yer tutmaktadır. Özellikle neden olan hastalığın prognozu, seyri ve sonuçları açısından ayırıcı tanıya giderken dikkatli olunmalı ve muhtemel morbiditelerin önüne geçmek için doğru tanıdan uzaklaşılmamalıdır. Kemik iliği ödemi belirlendiğinde akut travmatik ödemden stres kırığına, geçici osteoporozdan osteonekroza, kortikosteroid kullanım öyküsünden madde bağımlılığına kadar birçok hastalık akılda tutulmalıdır. Geçmişten günümüze dek, kemik iliği ödemi ve osteonekroz arasındaki neden sonuç ilişkisi sorgulanmıştır ve hala bu ilişki tartışmalıdır. Kemik iliği ödemi olan hastalar yakın takibe alınmalı, mutlaka osteonekroz ve diğer hastalıklar da akılda tutularak görüntüleme yöntemlerinin yardımıyla tanıya ulaşılması amaçlanmalı ve daha sonrasında da tanıya yönelik tedavi uygulanmalıdır.
\end{abstract}

Anahtar sözcükler: kemik iliği ödemi; osteonekroz; avasküler nekroz; geçici osteoporoz; kalça eklemi

emik iliği ödemi, birçok hastalıkta ortaya çıkabilmesi ve değişen düzeylerde ağrı ile birlikte görülmesi nedeniyle önemli bir patolojidir. Patofizyolojik olarak, kemik iliği ödeminin, damar içi basıncın arttığı durumlarda ortaya çıkan, kemik iliği kapiller hasarına bağlı olduğu bildirilmiştir. ${ }^{[1]}$ Travma tümör ve diğer birçok patoloji nedeniyle ortaya çıkan bu mekanizma sonucunda kapiller kaçış meydana gelmekte ve artan kemik içi basınçla kemik iliği çevresindeki sinirlerin irritasyonu ağrıya neden olmaktadır. ${ }^{[1]}$ Ayrıca sert (rijit) bir kemik kompartmanında damar dışı basınç artışı hücre ölümü ile osteonekroz gelişimine neden olmaktadır. ${ }^{[2]}$ Kemik iliği ödemi sıklıkla travma, geçici osteoporoz, osteonekroz, kıkırdak hasarı, stres kırıkları, enfeksiyon ve malignite gibi patolojilerle ortaya çıkabilir.
Bone marrow edema is a clinical finding that can occur in many different locations in the body and may be associated with different diseases. Osteonecrosis has an important place among these variable causes. Particular attention should be paid to the differential diagnosis in terms of the prognosis, course and consequences of the primary cause and the correct diagnosis should not be avoided in order to prevent possible morbidities. When bone marrow edema is identified, many diseases should be kept in mind, from acute traumatic edema to stress fracture, transient osteoporosis to osteonecrosis, or history of corticosteroid usage to drug addiction. The cause and effect relationship between bone marrow edema and osteonecrosis has been questioned from past to present, and this relationship is still controversial. Patients with bone marrow edema should be followed up closely, osteonecrosis and the other pathologies should be kept in mind, diagnosis should be made with the help of imaging methods, and then a diagnosis-oriented treatment should be applied.

Key words: bone marrow edema; osteonecrosis; avascular necrosis; transient osteoporosis; hip joint

\section{KEMiK íLiĞi ÖDEMi SENDROMU (Geçici Osteoporoz)}

Kemik iliği ödemi birçok farklı hastalıkta ve vücudun birçok farklı yerinde görülebilmektedir. Kemik iliği ödeminin en sık görüldüğü lokasyon ise proksimal femurdur. Daha önce "geçici osteoporoz" veya "geçici kemik iliği ödemi sendromu" diye adlandırılırken günümüzde ise "kemik iliği ödemi sendromu" adı daha sık kullanılan bu hastalığın osteonekroz ile ayrımı önemlidir. Geçici osteoporoz adlandırmasının nedeni bu hastalarda dual-enerji X-ray absorpsiyometri (DEXA) ölçümlerinin osteoporoz bulgusu vermesidir. ${ }^{[3]}$ Geçici osteoporoz, ilk olarak kadınlarda tanımlanmıştır ve özellikle peripartum döneminde ortaya çıktığı bildirilmiştir. ${ }^{[4,5]}$ Her ne kadar geçici osteoporoz kadınlarda tanımlanmış olsa da daha sık olarak erkeklerde görülmektedir. ${ }^{\left[{ }^{[6]}\right.}$

- Illetişim adresi: Op. Dr. Toygun Kağan Eren, Ankara Eğitim ve Araştırma Hastanesi, Ortopedi ve Travmatoloji Kliniği, Ankara Tel: 0533 - 4388853 e-posta: toyguneren@gmail.com

- Geliș tarihi: 7 Eylül $2020 \quad$ Kabul tarihi: 22 Eylül 2020 


\section{Osteonekroz}

Osteonekroz birçok farklı nedenle ortaya çıkabilir. Osteonekroz oluşumunda femur başı kanlanmasının bozulması önemlidir. ${ }^{[7]}$ En sık 3. ve 4. dekatlardaki genç erkeklerde görülür. \%72'ye varan oranda bilateral görülme sıklığı bildirilmiştir. ${ }^{\left[{ }^{[8]}\right.}$ Travmatik ve travmatik olmayan osteonekroz olarak ikiye ayrılır. Travmatik osteonekroz, özellikle travmatik kalça çıkığı ve proksimal femur kırıklarından sonra görülmektedir. ${ }^{[9]}$ Travmatik olmayan osteonekroz nedenleri ise, kortikosteroid kullanımı, alkolizm, hemoglobinopatiler, pankreatit, radyasyon, kemoterapi, depo hastalıkları, gebelik ve diğer idiyopatik nedenlerdir. ${ }^{[10]}$ Osteonekroz epifiz bölgesinde ortaya çıkarsa avasküler nekroz, metafiz ve diyafiz bölgelerinde oluşursa ise kemik iliği enfarktı olarak adlandırılır. ${ }^{[7]}$

Her iki patoloji de radyolojik görüntülemede kemik iliği ödemi bulgusu vermektedir. Prognozu ve tedavisi farklı olan bu iki hastalığın ayırıcı tanısında dikkatli olunmalıdır. Osteonekroz progresif bir hastalık olup, kemik nekrozu ve sonrasında eklem yüzeyinde çökme, daha sonrasında ise eklem dejenerasyonu gelişmesiyle, total kalça artroplastisi gereksinimi ortaya çıkarabilecek bir patolojidir. Kemik iliği ödemi sendromu ise konservatif tedavi ile takip edilebilen daha sınırlı ve ilerleyici olmayan bir hastalıktır.

\section{Görüntüleme}

Osteonekroz gelişiminin özellikle başlarında spesifik semptomlar ortaya çıkmaması nedeniyle erken evre osteonekroz tanısında görüntülemenin yeri çok önemlidir. Erken tanı konamaması durumunda eklem hasarı giderek artacak ve hem tedavi seçeneklerinin morbiditesi hem de maliyetleri artacaktır. Ayrıca ileri evre osteonekroz gelişimiyle eklem tamamen kaybedilip artroplasti seçeneğine mecbur kalınacaktır.

Osteonekroz görüntülemesinde, düz radyografiler, bilgisayarlı tomografi (BT), manyetik rezonans (MR) görüntüleme ve sintigrafi kullanılabilir. Erken evrelerde düz radyografiler bulgu vermeyebilirken, MR görüntüleme ve sintigrafi tanı açısından daha değerlidir. Ileri evre osteonekrozda ise düz radyografiler yeterli olup daha ileri görüntüleme seçeneklerine ihtiyaç yoktur. Erken evrelerde düz radyografilerde yamalı radyolusen veya sklerotik alanlar görülebilir. Daha ileri evrelerde ise subkondral kırı̆ın neden olduğu crescent (hilâl) bulgusu görülebilir. Bu bulgu eklem yüzü çökmesinin en erken belirtecidir. ${ }^{[7]} \mathrm{BT}$ nin ise görüntülemede destekleyici rolü vardır. BT, düz radyografilerden daha duyarlıdır ve MR uygulanamayan hastalarda yararlı olabilir. ${ }^{[11]}$

$M R$, sintigrafi ve diğer görüntüleme yöntemlerine göre daha duyarlıdır. Özellikle kemik iliği nekrozunu daha iyi ortaya koyar. (Şekil 1 ve 2) Aynı zamanda lezyon çevresindeki kemik iliği ödemini belirleyerek prognozu belirlemede ve tedavi seçiminde yararlı olur. T1 ağırlıklı görüntülerde osteonekrozun klasik görünümü femur başında normal yağ parlaklığı içindeki bir alanda azalmış kemik iliği sinyalidir ve bu alanın çevresinde iskemik kemiği gösteren, düşük sinyalli bir alan vardır. T2 ağırlıklı görüntülerde ise parlak bir çevre ile ortaya çıkan çift sinyal işareti vardır ve bu işaret osteonekroz için diagnostiktir. ${ }^{[12]}$ Subkondral kırıklar T1 ağırlıklı görüntülerde düşük yoğunluk, T2 ağırlıklı görüntülerde ise değişken sinyal karakteristiği gösterir. ${ }^{[13]}$ Osteonekrozun ilerleme miktarına göre kıkırdak hasarı, effüzyon ve femur başı düzleşmesi gibi bulgular da görülebilir. ${ }^{[12]}$ Osteonekroz varlığında hastalığın seyrini ve sonucunu belirleme açısından en önemli faktör etkilenen eklem yüzeyi alanının eklem yüzeyine oranıdır. ${ }^{[14]} \mathrm{Bu}$ patolojik bulgular ile osteonekroz görüntülemesine dayalı olarak Ficat ve Arlet sınıflandırması geçmişte sıklıkla kullanılmıştır. Daha sonrasında ise Steinberg bu sınıflandırmayı modifiye etmiştir (Tablo 1). ${ }^{[15]}$

Teknesyum-99m (Tc99m) MDP veya Tc99m sülfür kolloid ile radyonükleotid sintigrafi uygulanabilir. Osteonekrozun erken evresinde soğuk fotopenik alan görülebilir. Bu bulgu geçici osteoporozda görülmediği için avasküler nekroz adına neredeyse patognomoniktir. ${ }^{[16]}$ Osteonekrozun ileri evrelerindeyse sintigrafide artmış aktivite görülebilir.

Kemik iliği ödemi ve osteonekroz arasındaki ilişki tartışmalıdır. Kemik iliği ödeminin, osteonekrozun başlangıç bulgusu olduğu iddia edilmiş ve kemik iliği ödemi olan bazı hastalarda bu ödem tamamen geçebilirken bazı durumlarda ise kemik iliği ödemi osteonekroza dönüşebildiği bildirilmiştir. ${ }^{[17]} \mathrm{Bu}$ ayrımın yapılması önemlidir. Günümüzde ise kemik iliği ödeminin, avasküler nekrozun ileri aşamalarında görüldüğü ve kötü prognostik faktör olduğu kabul edilmektedir. ${ }^{[13]}$

Kalça ve diz ekleminde geçici kemik iliği sendromu hastalığı ile osteonekroz ayrımında dinamik kontrastlı manyetik görüntülemenin kullanılabileceği bildirilmiştir. Bu çalışmada geçici kemik iliği ödemi sendromu olan hastalarda yüksek plazma akışına bağlı olarak hiperperfüze bir alan olduğu, osteonekroz olan hastalarda ise belirlenebilen bir perfüzyon olmadan subkondral bir alan çevresinde yüksek plazma akışını gösteren bir çember olduğu raporlanmıştır. ${ }^{[18]}$ Yakın zamanda yayımlanan bir çalışmada, kemik iliği ödemi sendromu olan hastalardaki subkondral çizgi ve noktaların osteonekroza ilerlemediği bildirilmiştir. Ayrıca yazarlar, T1'de hipointens görünen alanların muhtemelen doku tamirini gösterdiğini öne sürmüşlerdir. ${ }^{[19]}$ 

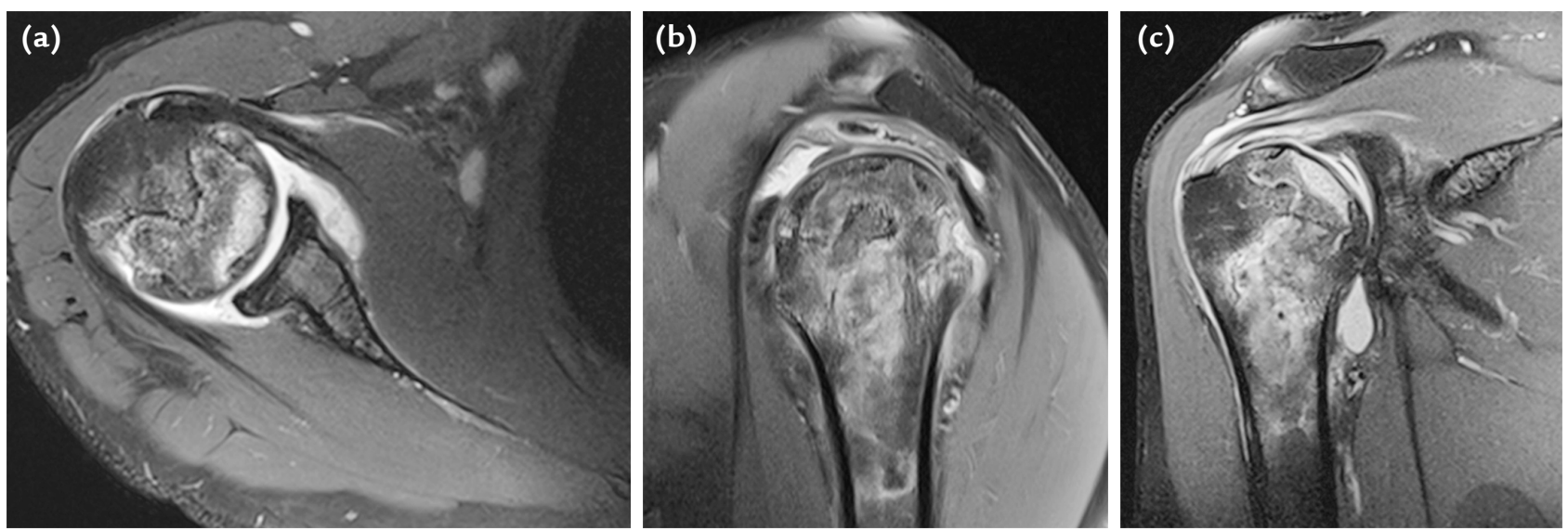

Şekil 1. a-c. Kırk yedi yaşında kadın hastanın, sağ omuz aksiyel (a), sagittal (b), koronal (c), turbo spin echo (TSE), yağ baskılı (FS) MR kesitleri. Sağ humerus başında osteonekroz ve kemik iliği ödemi görülmekte.
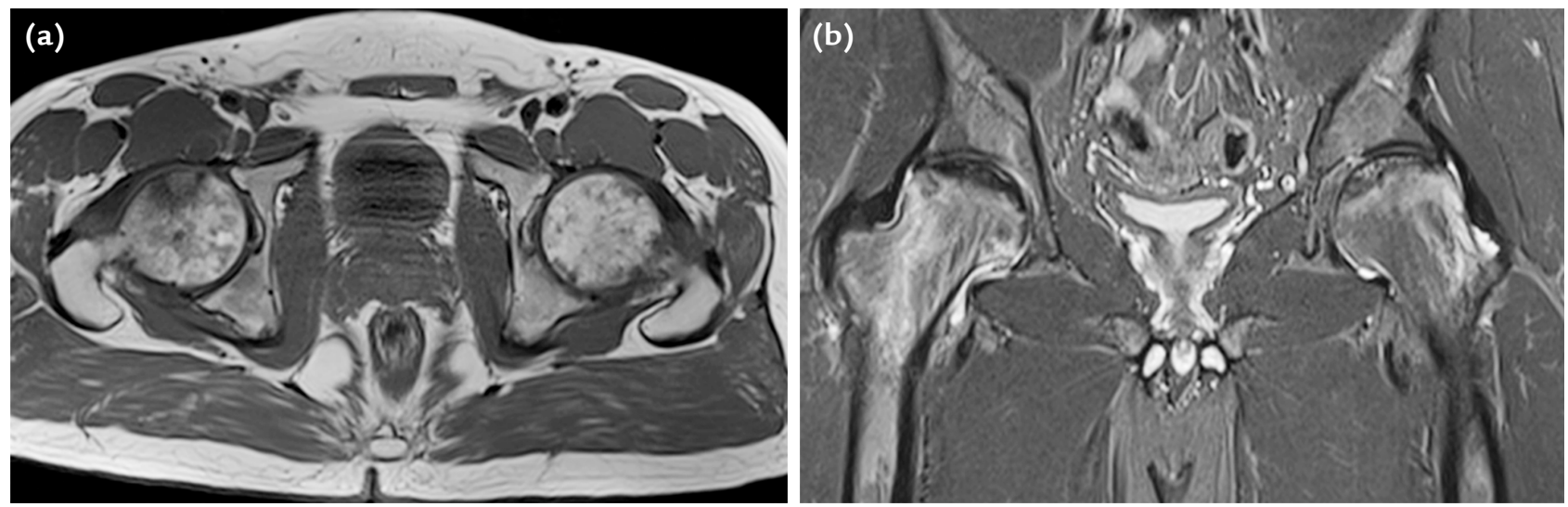

Şekil 2. a, b. Otuz bir yaşında erkek hastanın, bilateral kalça aksiyel TSE (a), koronal turbo inversion recovery magnitude (TIRM) (b) kesitleri. Bilateral femur başı osteonekrozu görülmekte.

Tablo 1. Kalça osteonekrozunda Steinberg sınıflandırması ${ }^{[15]}$

\begin{tabular}{cll}
\hline Evre & Radyografi & MR görüntüleme \\
\hline 0 & Normal & Normal \\
I & Normal & Anormal bulgular \\
II & Kistik veya sklerotik değişiklikler & Anormal bulgular \\
III & Hilâl (crescent) bulgusu (subkondral çökme) & Anormal bulgular \\
IV & Femur başı düzleşmesi: & Anormal bulgular \\
& $\quad$ Orta, $2-4 \mathrm{~mm}$ \\
& $\quad$ Ciddi, $>4 \mathrm{~mm}$ & \\
V & Eklemde daralma & Anormal bulgular \\
VI & ileri derece dejeneratif değişiklikler & Anormal bulgular \\
\hline
\end{tabular}

MR, manyetik rezonans.

Evre I-V arası femur başının eklem yüzeyinin etkilenme oranına göre alt gruplara ayrılır:

A (hafif), <\%15

B (orta), \%15-30

$C$ (ağır), > $\% 30$ 
Kim ve ark., histolojik olarak doğrulanmış femur başı osteonekrozu tanısı olan 200 hastanın MR görüntülerini incelemişler ve "bant işareti" oluşmadan önce kemik iliği ödemi oluşmadığını bildirmişlerdir. ${ }^{[20]}$ Benzer şekilde böbrek nakli yapılan hastalarda osteonekroz öncesi kemik iliği ödemi oluşmadığı ortaya konmuştur. ${ }^{[21,22]}$ Meier ve ark., kemik iliği ödeminin, osteonekrozun ileri aşamalarında ortaya çıktığını raporlamışlardır. ${ }^{[23]}$

\section{Tedavi}

Kemik iliği ödemi sendromu (geçici osteoporoz) tedavisinde konservatif yöntemler tercih edilmektedir. Uygun analjezikler, ekstremiteye yük vermeme ve istirahat gibi yöntemlerle hastalığın doğal seyri takip edilerek hastalar takip edilmekte ve zamanla iyileşme görülmektedir.

Osteonekroz tedavisi ise bisfosfonat uygulanması gibi konservatif tedavi seçeneklerinden, kordekompresyon; vaskülarize olan ve olmayan kemik greftleme, tantalum implantı gibi cerrahi tedavi seçenekleriyle tedavi edilebilir. Bu tedavi seçiminde önemli olan ise osteonekrozun evresidir. Özellikle erken evrelerde tanı koymak, eklemi korumak açısından önemlidir. Eğer osteonekroz ilerlerse ve eklem yüzü çökerse total kalça artroplastisi cerrahisi gerekecektir. ${ }^{[24]}$

\section{SONUÇ}

Kemik iliği ödemi klinikte sıklıkla karşımıza çıkan bir bulgudur. Birçok farklı nedenle ortaya çıkabilen bu bulgu farklı hastalıklardan kaynaklanabilmektedir. Kemik iliği ödemi basit istirahat yöntemleriyle tedavi edilebilirken, katastrofik sonuçlara yol açabilecek durumlarda da görülebilmektedir. Bu nedenle ayırıcı tanı çok önemlidir ve ayırıcı tanıda özellikle osteonekroz önemli bir yer tutmaktadır. Geçmişten günümüze dek neden sonuç ilişkisi sorgulanmıştır ve genel görüş her ne kadar kemik iliği ödeminin bir neden değil bir sonuç olduğu yönüne kaysa da bu ilişki hala tartışmalıdır. Kemik iliği ödemi olan hastalar yakın takibe alınmaII, mutlaka osteonekroz ve diğer hastalıklar da akılda tutularak görüntüleme yöntemlerinin yardımıyla tanıya ulaşı ıması amaçlanmalı daha sonrasında da tanıya yönelik tedavi uygulanmalıdır.

\section{KAYNAKLAR}

1. Eustace S, Keogh C, Blake M, Ward RJ, Oder PD, Dimasi M. MR imaging of bone oedema: mechanisms and interpretation. Clin Radiol 2001;56(1):4-12. Crossref

2. Hungerford DS, Lennox DW. The importance of increased intraosseous pressure in the development of osteonecrosis of the femoral head: implications for treatment. Orthop Clin North Am 1985;16(4):635-54. https://pubmed.ncbi.nlm. nih.gov/3903603/
3. Klontzas ME, Vassalou EE, Zibis AH, Bintoudi AS, Karantanas $\mathrm{AH}$. MR imaging of transient osteoporosis of the hip: an update on 155 hip joints. European J Radiol 2015;84(3):4316. Crossref

4. Curtiss PH Jr, Kincaid WE. Transitory demineralization of the hip in pregnancy. A report of three cases. J Bone Joint Surg Am 1959;41(7):1327-33. Crossref

5. Vassalou EE, Klontzas ME, Tsifountoudis IP, Spanakis K, Karantanas AH. Spectrum of skeletal disorders during the peripartum period: MRI patterns. Diagn Interv Radiol 2019 25(3):245-50. Crossref

6. Asadipooya K, Graves L, Greene LW. Transient osteoporosis of the hip: review of the literature. Osteoporos Int 2017;28(6):1805-16. Crossref

7. Murphey MD, Foreman KL, Klassen-Fischer MK, Fox MG, Chung EM, Kransdorf MJ. From the radiologic pathology archives imaging of osteonecrosis: radiologic-pathologic correlation. Radiographics 2014;34(4):1003-28. Crossref

8. Assouline-Dayan Y, Chang C, Greenspan A, Shoenfeld $\mathrm{Y}$, Gershwin ME. Pathogenesis and natural history of osteonecrosis. Semin Arthritis Rheum 2002;32(2):94-124. Crossref

9. Solomon L. Mechanisms of idiopathic osteonecrosis. Orthop Clin North Am 1985;16(4):655-67. https://pubmed.ncbi. nlm.nih.gov/4058895/

10. Sweet DE, Madewell JE. Osteonecrosis. Pathogenesis. In: Resnick D, Niwayama G, editors. Diagnosis of Bone and Joint Disorders, Vol. 5, 3rd ed. Philadelphia: WB Saunders; 1994. p.3445-94.

11. Magid D, Fishman EK, Scott WW Jr, Brooker AF, Arnold WP, Lennox DW, Siegelman SS. Femoral head avascular necrosis: $\mathrm{CT}$ assessment with multiplanar reconstruction. Radiology 1985;157(3):751-6. Crossref

12. Witte $\mathrm{DH}$. Magnetic Resonance Imaging in Orthopaedics. In: Campbell WC, Canale ST, Beaty JH, editors. Campbell's Operative Orthopaedics, 12th ed. Philadelphia: Mosby/ Elsevier; 2008. p.130-9. Crossref

13. Vassalou EE, Spanakis K, Tsifountoudis IP, Karantanas AH. MR Imaging of the Hip: An Update on Bone Marrow Edema. Semin Musculoskelet Radiol 2019;23(3):276-88. Crossref

14. Lafforgue P, Dahan E, Chagnaud C, Schiano A, Kasbarian M, Acquaviva PC. Early-stage avascular necrosis of the femoral head: MR imaging for prognosis in 31 cases with at least 2 years of follow-up. Radiology 1993;187(1):199-204. Crossref

15. Steinberg ME, Hayken GD, Steinberg DR. A quantitative system for staging avascular necrosis. J Bone Joint Surg $\mathrm{Br}$ 1995;77-B(1):34-41. Crossref

16. Guerra JJ, Steinberg ME. Distinguishing transient osteoporosis from avascular necrosis of the hip. J Bone Joint Surg Am 1995;77(4):616-24. Crossref

17. Hofmann S, Schneider W, Breitenseher M, Urban M, Plenk H Jr. Transient osteoporosis as a special reversible form of femur head necrosis. Der Orthopade 2000;29(5):411-9. Crossref

18. Geith $T$, Niethammer $T$, Milz $S$, Dietrich $O$, Reiser M, BaurMelnyk A. Transient Bone Marrow Edema Syndrome versus Osteonecrosis: Perfusion Patterns at Dynamic Contrastenhanced MR Imaging with High Temporal Resolution Can Allow Differentiation. Radiology 2016;283(2):478-85. Crossref

19. Geith T, Stellwag A-C, E Muller P, Reiser M, Baur-Melnyk A. Is bone marrow edema syndrome a precursor of hip or knee osteonecrosis? Results of 49 patients and review of the literature. Diagn Interv Radiol 2020 26(4):355-62. Crossref 
20. Kim YM, Oh HC, Kim HJ. The pattern of bone marrow oedema on MRI in osteonecrosis of the femoral head. J Bone Joint Surg Br 2000;82-B(6):837-41. Crossref

21. Kubo T, Yamazoe $S$, Sugano N, Fujioka M, Naruse $S$, Yoshimura N, Oka T, Hirasawa Y. Initial MRI findings of nontraumatic osteonecrosis of the femoral head in renal allograft recipients. Magn Reson Imaging 1997;15(9):1017-23. Crossref

22. Fujioka M, Kubo T, Nakamura F, Shibatani M, Ueshima K, Hamaguchi H, Inoue S, Sugano N, Sakai T, Torii Y, Hasegawa Y, Hirasawa Y. Initial changes of non-traumatic osteonecrosis of femoral head in fat suppression images: bone marrow edema was not found before the appearance of band patterns. Magn Reson Imaging 2001;19(7):985-91. Crossref
23. Meier R, Kraus TM, Schaeffeler C, Torka S, Schlitter AM, Specht K, Haller B, Waldt S, Rechl H, Rummeny EJ, Woertler $\mathrm{K}$. Bone marrow oedema on MR imaging indicates $\mathrm{ARCO}$ stage 3 disease in patients with AVN of the femoral head. Eur Radiol 2014;24(9):2271-8. Crossref

24. Marker DR, Seyler TM, Ulrich SD, Srivastava S, Mont MA. Do modern techniques improve core decompression outcomes for hip osteonecrosis? Clin Orthop Relat Res 2008;466(5):1093-103. Crossref 